\title{
Titanium plate fixation for sternal dehiscence 10 years after cardiac surgery
}

\author{
Randa Hazam MD, Muath Alsharif MD, Ahmed Taha MD, Bharat Khandheria MD
}

\section{Case summary}

An 83-year-old man with a history of coronary artery disease was admitted to our hospital with a non ST-segment elevation myocardial infarction. The patient's chest $\mathrm{x}$-ray was very unusual showing chest wall fixation with titanium plates (Figure). He recalled that in his 20 s he had a right breast lumpectomy for a benign tumor which left some scar tissue. At the age of 66 , he had an acute myocardial infarction with multi-vessel disease requiring coronary artery bypass grafting (CABG). The closure of the sternum was done with the traditional wire cerclage method. The patient returned 10 years later with chest pain, and computed tomography of the thorax showed chest wall instability and a fibrous nonunion of the chest wall and sternum secondary to sternal wire loosening. Based on these findings, he required removal of the scar and chest wall stabilization using internal hardware with titanium plates and an overlying muscle flap. Longterm follow-up showed a stable sternum and no chest symptoms.

\section{Discussion}

The standard closure technique after median sternotomy is to join the two parts using steel wires (i.e., figure-of eight fashion wiring). However, this closure technique has been associated with several serious complications that have prompted surgeons to study new closure methods. These complications include sternal instability (movement of the sternum at the site of sternal division), dehiscence (re-opening of the wound at the site of the sternal division), and mediastinitis. ${ }^{1}$

Sternal dehiscence with or without infection is a rare but serious complication of median sternotomy. ${ }^{2}$ It

Corresponding author: Randa Hazam

Contact Information: Randa.hazam@ttuhsc.edu

DOI: 10.12746/swrccc.v7i30.568 carries a high risk of mortality following major cardiac surgery with an incidence rate of $0.5 \%$ to $5.0 \% .^{3-6}$ It usually occurs in the immediate postoperative period. In cases with infection and dehiscence, conventional treatment includes wound debridement, wound vacuum therapy, and sternal rewiring. ${ }^{6}$ This rewiring often fails to achieve sternal healing and stability due to poor sternum quality. Failed rewiring can lead to partial or complete sternum removal and consequent sternal defects. ${ }^{7}$ The rate of rewiring failure can be as high as $45 \%{ }^{8}$

A new titanium plate fixation system seems to be an excellent and safe alternative in case of sternal dehiscence. Multiple case series studies have demonstrated good clinical outcomes with titanium plates fixation. ${ }^{9-11} \mathrm{~A}$ retrospective cohort study that compared the effectiveness of titanium plate fixation with a conventional approach in the treatment of deep sternal wound infection showed titanium plate fixation had a favorable clinical outcome. ${ }^{12}$ Another retrospective study compared Titanium Plate Fixation versus Conventional Closure for Sternal Dehiscence after Cardiac Surgery and showed that titanium plate fixation was superior in stabilizing the sternal bone when compared to conventional refixation methods. ${ }^{2}$

Two recent studies suggest that titanium plate fixation can provide a primary method for sternotomy closure in patients at risk to develop sternal non-union and infection. ${ }^{13,14}$ Both studies compared primary sternotomy closure after CABG using rigid plate fixation with titanium versus wire cerclage and reported that titanium fixation improved sternal healing with fewer sternal complications.

In conclusion, titanium plate fixation combined with appropriate debridement and flap interposition is very effective for the treatment of sternal dehiscence following major cardiac surgery. ${ }^{15}$ There is also some preliminary evidence to suggest this may be a better primary closure method, but the cost and the training of the surgeons may be the limiting factors. Our case with an excellent outcome supports the current 


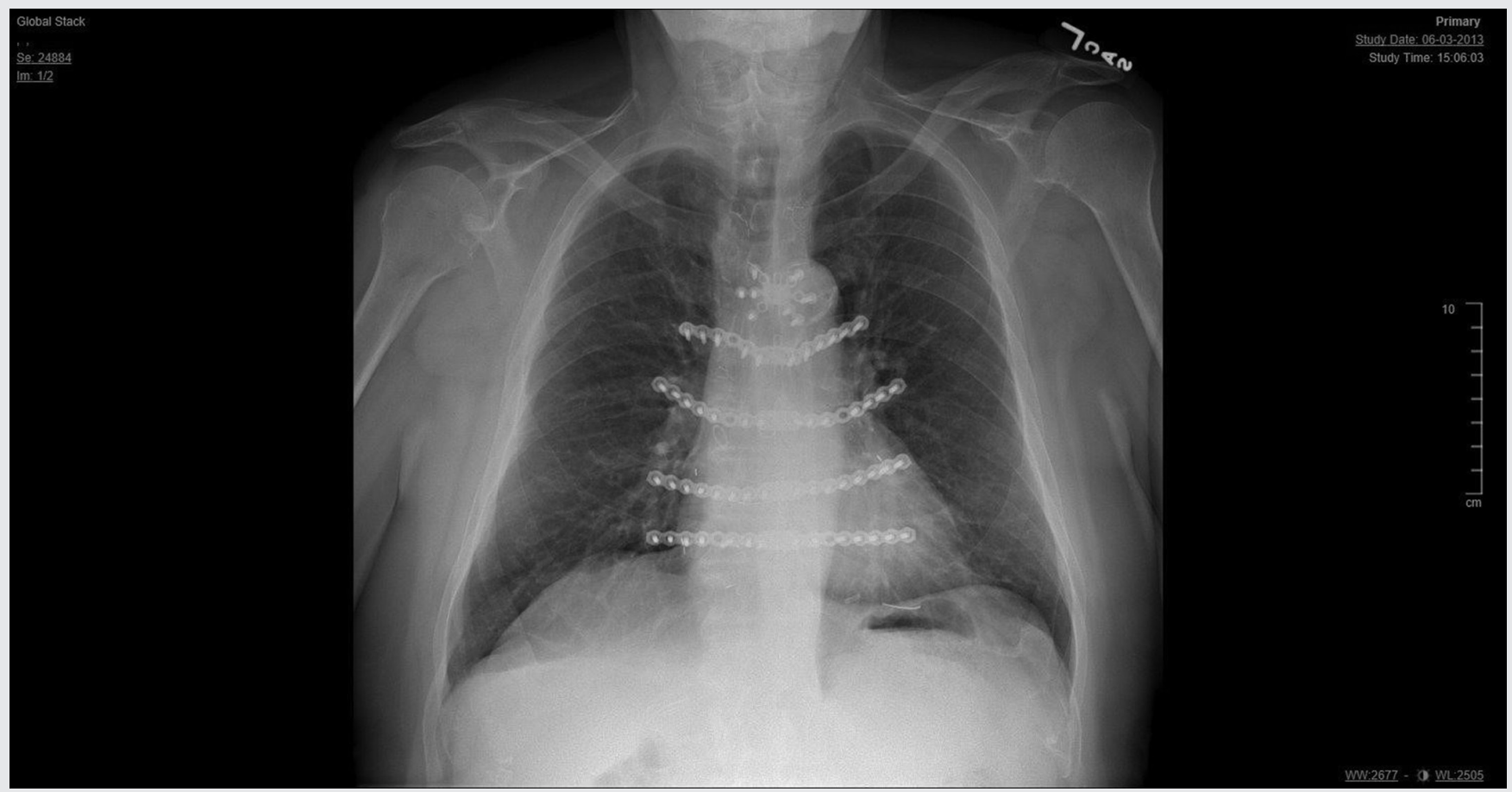

Figure.

literature that sternal plate fixation is an effective approach for secondary closure. However, a randomized control trial is needed to better compare this approach with conventional treatment as a primary closure method.

Keywords: Titanium plate, sternal dehiscence, cardiac surgery

Article citation: Hazam R, Alsharif M, Taha A, Khandheria B. Titanium plate fixation for sternal dehiscence 10 years after cardiac surgery. The Southwest Respiratory and Critical Care Chronicles 2019;7(30):73-75

From: Department of Internal Medicine, Texas Tech University Health Sciences Center, Amarillo, Texas

Submitted: $7 / 3 / 2019$

Accepted: 7/5/2019

Reviewer: Kenneth Nugent MD

Conflicts of interest: none

This work is licensed under a Creative Commons Attribution-ShareAlike 4.0 International License.

\section{REFERENCES}

1. Pinotti, K, El Dib R, Cataneo D, et al. Sternal fixation techniques following sternotomy for preventing sternal wound complications. Cochrane Database of Systematic Reviews 2017 (5); CD010999. doi:10.1002/14651858.CD010999.pub2

2. JongbloedL, Sonker, Kloppenburg G, etal.Titanium plate fixationversusconventionalclosureforsternaldehiscenceaftercardiac surgery. Thoracic Cardiovascular Surgeon 2016;65(04): $338-342$.

3. Losanoff J. Primary closure of median sternotomy: techniques and principles. Cardiovascular Surg 2002;10(2):102-110.

4. Douville E, Asaph J, Dworkin R, et al. Sternal preservation: a better way to treat most sternal wound complications after cardiac surgery. Ann Thoracic Surg 2004;78(5):1659-1664.

5. El Oakley R, Wright J. Postoperative mediastinitis: Classification and management. Ann Thoracic Surg 1996;61(3):1030-1036.

6. De Brabandere K, Jacobs-Tulleneers-Thevissen D, Czapla $\mathrm{J}$, et al. Negative pressure wound therapy and laparoscopic omentoplasty for deep sternal wound infections after median sternotomy. Tex Heart Inst J 2012;39:367-71.

7. Immer F, Durrer M, Mühlemann K, et al. Deep sternal wound infection after cardiac surgery: modality of treatment and outcome. Ann Thor Surg 2005;80(3):957-961. 
8. Assmann A, Boeken U, Feindt P, et al. Vacuum-assisted wound closure is superior to primary rewiring in patients with deep sternal wound infection. Thoracic Cardiovascular Surgeon 2011;59(01):25-29.

9. Ruberg R. Sternal wound reconstruction with transverse plate fixation. Yearbook of Plastic and Aesthetic Surgery, 2007, p.78.

10. Voss B, Bauernschmitt R, Will A, et al. Sternal reconstruction with titanium plates in complicated sternal dehiscence. Euro J Cardio-Thor Surg 2008;34(1);139-145.

11. Huh J, Bakaeen F, Chu D, et al. Transverse sternal plating in secondary sternal reconstruction. J Thoracic Cardiovascular Surg 2008;136(6):1476-1480.

12. Wang W, Wang S. Titanium plate fixation versus conventional approach in the treatment of deep sternal wound infection. J Cardiothoracic Surg 2016 Apr 8; 11:46. doi: 10.1186/s13019-016-0458-3.

13. Kim W, Kim J, Kim G, et al. Titanium plate fixation for sternal dehiscence in major cardiac surgery. Korean $\mathrm{J}$ Thoracic Cardiovascular Surg 2013;46(4):279-284.

14. Allen KB, Icke KJ, Thourani VH, et al. Sternotomy closure using rigid plate fixation: a paradigm shift from wire cerclage. Ann Cardiothoracic Surg 2018;7(5):611-620.

15. Elghonemy YF, Hussein MA. Titanium plate fixation versus wire sternal closure in coronary artery bypass graft patients: Need for rigid sternal fixation. J Egyptian Soc CardioThoracic Surg 2016;24:150-158. 